\title{
Compreensão, escuta e expressão das emoções de docentes de uma instituição de ensino técnico e superior do sul do Brasil: uma contribuição da Análise Transacional
} (AT)

\author{
Understanding, listening and expressing emotions by teachers at a technical and higher education \\ institution in southern Brazil: a contribution from Transactional Analysis (AT)
}

Comprensión, escucha y expresión de emociones por parte de los docentes de una institución

técnica y de educación superior en el sur de Brasil: una contribución del Análisis Transaccional

Recebido: 26/06/2021 | Revisado: 04/07/2021 | Aceito: 06/07/2021 | Publicado: 16/07/2021

\author{
Maria Lucia Rodrigues Falk \\ ORCID: https://orcid.org/0000-0003-1507-6131 \\ FACTUM Faculdade e Escola Técnica, Brasil \\ E-mail: mluciafalk@gmail.com \\ Marlene Zwierewicz \\ ORCID: https://orcid.org/0000-0002-5840-1136 \\ Universidade Alto Vale do Rio do Peixe, Brasil \\ E-mail: marlenezwie@yahoo.com.br
}

\begin{abstract}
Resumo
A educação emocional aplicada no contexto da educação visa desenvolver o autoconhecimento sobre as emoções, buscando a melhoria da qualidade de vida tanto do educador quanto do educando. Assim, este estudo teve como objetivo analisar a influência do Curso 101 - Introdução à Análise Transacional (AT) na compreensão, escuta e expressão das emoções de docentes de uma instituição de cursos técnicos e superiores do sul do Brasil. Teoricamente, o estudo está pautado em autores como Berne, Steiner, Erskine, entre outros. Definindo-se como uma pesquisa avaliativa, apoiada pela metodologia quantitativa, o estudo contou com a participação de 20 docentes dessa instituição. Para a coleta de dados, foi utilizado o Questionário de Consciência Emocional (Steiner e Perry, 1997), aplicado como pré-teste e pós-teste. O resultado da pesquisa demonstra, pelo Teste T de Wilcoxon, a ampliação do nível de consciência emocional, especificamente no que tange à expansão dos níveis de empatia e interatividade.
\end{abstract}

Palavras-chave: Análise transacional; Emoções; Educação; Educação emocional; Ensino.

\begin{abstract}
Emotional Education applied in the educational context aims to develop self-knowledge about emotions, seeking to improve the quality of life of both the educator and the student. Thus, this study aimed to analyze the influence of 'Course 101 - Introduction to Transactional Analysis (AT)' in the understanding, listening and expression of emotions in teachers of an institution of technical and higher courses in southern Brazil. Theoretically, the study is based on authors such as Berne, Steiner, Erskine, among others. Defined as an evaluative research supported by the quantitative methodology, the study counted on the participation of 20 professors from this institution. For data collection, the Emotional Awareness Questionnaire (Steiner and Perry, 1997) was used, applied as a pre-test and post-test. The result of the research demonstrates, through the Wilcoxon T Test, the expansion of the level of 'Emotional Awareness', specifically with regard to the expansion of the levels of 'Empathy' and 'Interactivity'.
\end{abstract}

Keywords: Transactional analysis; Emotions; Education; Emotional education; Teaching.

\section{Resumen}

La Educación Emocional aplicada en el contexto educativo mira desarrollar el autoconocimiento sobre las emociones, buscando mejorar la calidad de vida tanto del educador como del alumno. Así, este estudio tuvo como objetivo analizar la influencia del "Curso 101 - Introducción al Análisis Transaccional (TA)" en la comprensión, escucha y expresión de emociones en docentes de una institución de cursos técnicos y superiores en el sur de Brasil. Teóricamente, el estudio se basa en autores como Berne, Steiner, Erskine, entre otros. Definiéndose como una investigación evaluativa, sustentada en la metodología cuantitativa, el estudio contó con la participación de 20 profesores de esta institución. Para la recolección de datos se utilizó el Cuestionario de Conciencia Emocional (Steiner y Perry, 1997), aplicado como pre-test y post-test. El resultado de la investigación demuestra, a través del Test 
Wilcoxon T, la expansión del nivel de 'Conciencia Emocional', específicamente en lo que respecta a la expansión de los niveles de 'Empatía' e 'Interactividad'.

Palabras clave: Análisis transaccional; Emociones; Educación; Educación emocional; Enseñanza.

\section{Introdução}

Emoções são cruciais para o pensamento se efetivar, pois influenciam na tomada rápida de decisões que exigem firmeza, assim como para se relacionar e enfrentar desafios ao longo da vida. Enquanto isso, a perturbação emocional pode ser destrutiva ao ponto de atormentar e mutilar até a capacidade da reflexão e criação. Portanto, o gerenciamento das emoções pode contribuir para a capacidade de enfrentamento de situações adversas e, consequentemente, para o bem-estar individual e coletivo.

Assim, por sua complexidade, as emoções não são mais compreendidas como uma reação única, mas como um processo que envolve múltiplas variáveis. Elas podem ser definidas como "uma condição complexa envolvendo estruturas neurais na percepção Emocional através de expressões corporais, que provoca alterações em várias áreas do funcionamento psicológico e fisiológico, preparando o indivíduo para a ação" (Atkinson \& Adolphs, 2005, p. 150).

No contexto escolar, tradicionalmente, não se contemplam saberes diretamente relacionados ao desenvolvimento das dimensões afetiva e emocional, que tendem a ficar sob a responsabilidade da família. A educação emocional envolve saberes que precisam ser desenvolvidos primeiramente junto aos docentes, para que estes possam propor metodologias que contemplem as competências (habilidades e atitudes) desejáveis no desenvolvimento da inteligência emocional de crianças e adolescentes.

A reflexão sobre os saberes necessários ao desenvolvimento da educação emocional retrata um desafio requisitado à formação docente neste início de século. Muitos profissionais não se sentem seguros para lidar com aspectos emocionais e sua aplicação em sala de aula, pois sua formação inicial ou continuada nem sempre contempla a dimensão emocional com profundidade.

Como resposta à ausência de uma formação, os docentes podem desenvolver reações neurofisiológicas diante de situações estressantes que dificultam o trabalho em sala de aula. São respostas a situações que, para Rebolo e Bueno (2014), decorrem de insatisfações que eles experimentam em sua profissão, cujas causas incluem condições adversas no trabalho como conflitos ou violência (Sales, 2020).

Além disso, em sociedades como a nossa, a desvalorização dos professores, os baixos salários e as condições adversas de trabalho docente contribuem para o aumento das insatisfações. "Nas duas últimas décadas, maior atenção tem sido dada às questões do denominado mal-estar docente, envolvendo o sofrimento, o burnout e a insatisfação que os professores experimentam em sua profissão" (Rebolo \& Bueno, 2014, p. 323).

Steiner e Perry (1997) defendem que as emoções são inatas, geradas na porção límbica, primitiva e reptiliana de nosso cérebro. Apesar de considerarem que emoções como medo, afeto, raiva, tristeza e alegria, por exemplo, seriam lembretes de nossa natureza animal, os autores também afirmam que elas podem ser gerenciadas, desde que exista predisposição e apoio formativo.

Nesse sentido, destaca-se que assumir a responsabilidade pelas nossas emoções é uma atitude autotransformadora. A capacidade de gerenciar as emoções quando elas afloram é uma condição que influencia no cuidado consigo e nas relações com as outras pessoas. Trabalhada desde os primeiros anos de vida, pode favorecer o desenvolvimento socioemocional, desde que a escola assim o permita e atue como um espaço de acolhimento, garantindo que os estudantes possam descobrir e expressar suas emoções de maneira consciente (Silva, 2018). 


\section{A Escuta Empática, a Motivação e as Contribuições da Formação Docente}

Para uma melhor compreensão daquilo que se apresenta diariamente numa sala de aula, na relação dialógica entre docente e estudante, faz-se necessária uma escuta empática, mediante a qual o tom de voz, os gestos e a expressão corporal/facial nos indicam como a interação está acontecendo. A escuta empática implica numa qualidade entre assistir ao que está acontecendo dentro de si mesmo e ao que acontece com o outro. Nesse processo, a abertura ao diálogo promove o contágio emocional, sendo que empaticamente ambos são capazes de interpretar analiticamente a experiência (Steiner \& Perry, 2000).

$\mathrm{Na}$ contemporaneidade, os debates voltados ao fazer docente têm ganhado amplitude nas organizações escolares, evidenciando os desafios da docência. Nesse cenário, acentua-se a relevância de iniciativas de formação que discorram sobre sua participação nos processos de apropriação de posturas mais assertivas para o preparo do futuro educador (Ávila \& Souza, 2020).

A função docente, que deverá ter a sensibilidade necessária para transpor as barreiras de seu próprio conhecimento e de sua prática em sala de aula, pressupõe não somente a mera transmissão de conhecimentos, mas, também, a capacidade de escutar e motivar os estudantes para que aprendam e se desenvolvam integralmente. Essa condição é considerada determinante na relação entre docentes e estudantes, ela se constitui como "uma força interior que estimula, dirige, mobiliza a pessoa para uma ação com entusiasmo" (Camargo, Camargo \& Souza, 2019, p. 599).

A motivação tem sido considerada decisiva na explicação do comportamento escolar dos estudantes, em particular de sua aprendizagem. Quanto motivado, o estudante tende a ser mais consciente e responsável consigo, mostrando sua capacidade de ser, sentir, pensar e agir. Segundo Piccinino, a motivação é uma força que leva as pessoas a crescerem e evoluírem. A capacidade que os seres humanos possuem de se reinventar, de buscar novas perspectivas é o que faz cada um ser único (Piccinino, 2018).

O atual desafio - o mais urgente de nosso sistema educacional - está em preparar as pessoas para lidar com as incertezas, especialmente as decorrentes desta época pandêmica ímpar, cujos reflexos incluem problemas de saúde, em parte derivados da redução das atividades físicas e do confinamento (Ammar, et al., 2020; Brasch, et al., 2020).

Além disso, os docentes devem ser provocados a desenvolver habilidades para lidar com as mais variadas situações de intolerâncias, como de gênero, crenças e valores. Para esse enfrentamento, são necessários processos de ensino e de aprendizagem que articulem alternativas mais efetivas, porque ainda existe afastamento entre a teoria e a prática.

Nos últimos anos, tem vindo a crescer um sentimento de insatisfação, que resulta da existência de uma distância profunda entre as nossas ambições teóricas e a realidade concreta das escolas e dos professores, como se houvesse um fosso intransponível entre a universidade e as escolas, como se a nossa elaboração acadêmica pouco tivesse contribuído para transformar a condição socioprofissional dos professores (Nóvoa, 2017, p. 1108-1109).

Assim também acontece com a aprendizagem, que presume uma reconstrução diária de saberes de maneira consciente e sistemática. Isso porque a estrutura de representações de cada indivíduo é construída ao longo de sua história pessoal, na ampliação continuada de vivências. Dessa forma, ensinar representa definir situações nas quais os estudantes possam reformular conhecimentos, atitudes e habilidades, tornando-se aprendizes e protagonistas daquilo que vivem na relação entre experiência e saber.

Mas, como essa reconstrução diária de saberes são se restringe apenas aos estudantes, aprender a educar também é aprender a educar-se de forma gradativa e complacente. A preparação dos docentes para essas demandas requer uma transformação dos modos tradicionais de formação nas áreas de conhecimento. Por isso, "É preciso reconhecer as deficiências 
científicas e a pobreza conceptual dos programas atuais de formação de professores" (Nóvoa, 2017, p. 111). Permanece, portanto, a necessidade de preparar melhor os professores para os enfrentamentos da vida, para que melhores resultados sejam obtidos na escola e nos processos pessoais. Esse preparo inclui o estímulo à capacidade de ampliar a escuta empática, indispensável para compreender o que ocorre com os outros e consigo.

Torna-se evidente que escola necessita rever com urgência a sua prática educativa com vistas à adoção de proposições educativas que considerem as noções de liberdade, igualdade, dignidade humana, democracia, moral, de responsabilidade social passando assim a valorizar a importância da formação do indivíduo conhecedor dos seus direitos, crítico, ativo e transformador da realidade. As instituições escolares precisam urgentemente aderir às novas transformações sociais e preparar os alunos a enfrentarem os conflitos que fazem parte do cotidiano (Marques; Fraguas, 2021, p.11)

A escola, por si, já é um espaço inesgotável para a aprendizagem, mas esse espaço se torna ainda mais potente quando demonstra acolhimento para os jovens se expressarem. Isso implica que a formação docente acompanhe "as novas demandas sócio-históricas" que a realidade apresenta, incluindo também reflexões críticas sobre o enfrentamento do cotidiano (Reis, 2018, p. 43). Assim, a formação dos professores é um dos temas mais importantes dentre as políticas públicas para a educação, uma vez que os desafios colocados a esses profissionais exigem que o trabalho educativo leve em consideração múltiplos componentes.

Por um lado, as políticas educacionais e as diretrizes organizacionais e curriculares são portadoras de intencionalidades, ideias, valores, atitudes e práticas que vão influenciando as escolas e seus profissionais na configuração das práticas formativas dos educandos, determinando um tipo de sujeito a ser educado. Por outro, os profissionais das escolas podem aderir ou resistir a tais políticas e diretrizes do sistema escolar ou dialogar com elas e formular, colaborativamente, práticas formativas e inovadoras em vista de outro tipo de sujeito a ser educado (Libâneo, Oliveira \& Toschi, 2017, p. 24).

Assim, uma formação docente que contemple a diversidade não pode se eximir do papel da escuta e do acolhimento dos mais jovens. Isso requer dos profissionais destreza em lidar com as diferenças e habilidades para o atendimento da sociedade contemporânea, dando um novo sentido para o fazer pedagógico (Ávila \& Souza, 2020).

Uma das possibilidades existentes para contribuir com a formação docente consiste no desenvolvimento do Curso 101 - Introdução à Análise Transacional (AT). Esse curso contribui com a educação emocional em três dimensões: a compreensão, a escuta empática e a expressão produtiva das emoções (Steiner \& Perry, 1997). Nele, propõe-se qualificar as relações interpessoais e expandir os níveis de consciência emocional dos docentes. O curso é certificado pela União dos Analistas Transacionais (UNAT-Brasil) e ministrado por Analistas Transacionais Certificados, sendo seu conteúdo o mesmo em todos os países (UNAT, 2020).

Neste artigo, sistematizam-se resultados de uma pesquisa envolvendo esse curso. $\mathrm{O}$ objetivo do estudo foi analisar sua influência na compreensão, escuta e expressão das emoções de docentes de uma instituição de cursos técnicos e superiores do sul do Brasil, os quais atuam, simultaneamente, nas áreas de saúde e educação.

A AT estuda a forma como as pessoas pensam, sentem, agem e se relacionam, sendo um método muito eficaz para compreender o ser humano e propor soluções preventivas e transformadoras. Para isso, utiliza conceitos que possibilitam aos indivíduos conhecerem melhor o seu funcionamento e o dos outros. Isso contribui para que compreendam melhor os seus relacionamentos e percebam aquilo que deve ser mudado para melhorá-los (Berne, 1988).

Segundo a definição da International Transactional Analysis Association (ITAA, 2021, p. 1), a AT é uma teoria criada pelo psiquiatra canadense Eric Berne, que contempla certos "conceitos-chave que os profissionais usam para ajudar 
clientes, alunos e sistemas a analisar e mudar os padrões de interação que interferem na realização das aspirações de vida". É entendida como uma teoria da personalidade, uma psicoterapia sistemática para o crescimento e a mudança pessoal, assim como uma filosofia de vida. Faz parte dela um conjunto de técnicas de mudança positiva que possibilita uma tomada de posição mais efetiva (Berne, 1988). A AT trabalha basicamente tentando recuperar capacidades que considera inatas ao ser humano, entendendo que elas podem ser perdidas de acordo com vivências e situações estressantes e traumáticas sofridas principalmente durante a infância.

\section{Contextualizando a AT}

A AT tem vinculação com vários conceitos, entre eles: Estados do Ego, Transações, Estruturação do tempo, Jogos Psicológicos, Carícias, Síndrome da passividade (Comportamentos passivos, Desqualificação), Posição existencial e Script. Esses conceitos são discutidos a seguir, evidenciando-se sua relevância para a escuta empática.

Um dos conceitos básicos da AT constitui-se pelos Estados de Ego (EDE), aliados ao conhecimento da história pessoal do indivíduo e ao seu comportamento para estabelecer um diagnóstico pessoal e grupal (Berne, 1988). Os EDE constituem o sistema de sentimentos de cada indivíduo, representando sua estrutura interna ou personalidade, sendo que os EDE Pai, Adulto e Criança, e a interação entre eles, formam a base da teoria da AT e se definem como um padrão de pensamento e sentimento correspondente a um comportamento (Berne, 1988). O EDE pai é o reservatório de normas e valores, de conceitos e modelos de conduta. Esse EDE está sujeito a influências culturais e impõe à pessoa ações, regras e programas de conduta. O EDE Criança surge logo que se nasce. É o primeiro EDE a emergir no ser humano e representa as emoções básicas como alegria, amor, prazer, tristeza, raiva e medo. O EDE Adulto é a parte da personalidade do indivíduo que recebe informações de fora para dentro, analisa-as e toma decisões com base no seu banco de dados.

Quanto à estruturação de tempo, existem seis formas utilizadas pelas pessoas ao longo da vida. Essas formas de estruturar o tempo têm uma relação com a quantidade e a qualidade dos relacionamentos, são elas: isolamento, rituais, atividades, passatempo, Jogos Psicológicos e intimidade. Segundo Berne, elas caracterizam o tipo de interação que escolhemos ter com as outras pessoas.

Os Jogos Psicológicos são "conjuntos de Transações ulteriores, repetitivas por natureza, com um desfecho bem definido" (Berne, 1988, p. 34). Estes são compreendidos também como "uma série de lances com ciladas ou truque no meio ou no fim" (Berne, 1977, p. 49). O conceito de Jogos Psicológicos por meio do Triângulo dramático foi desenhado por Karpman (1968). Os jogos ocorrem mediante a negociação entre três pessoas ou grupos de pessoas. Em cada vértice desse triângulo encontram-se três forças (perseguidor, salvador e vítima). Estes três papéis podem ser dispostos num triângulo, para indicar como as pessoas trocam de papéis, que "São intercambiáveis bem como os sentimentos que os acompanham" (Steiner, 1976, p. 146).

Oposto aos Jogos está o conceito de Carícias. O primeiro possui uma motivação oculta e desonesta, já a Carícia é uma unidade de reconhecimento necessária à vida tanto quanto outras necessidades biológicas básicas (Steiner, 1980). Ao se referir à Carícia, Steiner (1980, p. 111) traz a teoria da economia ao compará-la ao que acontece em outras economias, ou seja, "o rico fica mais rico e o pobre fica mais pobre, enquanto a maioria precisa lutar diariamente para atender as suas necessidades". Assim, muitas pessoas vivem com a ideia de economizar Carícias, não oferecem elogios nem reconhecimento. Steiner reforça que essa economia não dá a permissão para aceitar ou para rejeitar as Carícias negativas. Nessa escassez, as injunções básicas são: "Não dê Carícias (a si ou aos outros); Não peça Carícias; Não aceite Carícias; Não rejeite as negativas" (Steiner, 1976, p. 116 e 1980, p. 112). Quando temos a abundância de Carícias, não existe a palavra "não". As pessoas dão estímulos, pedem, aceitam quando e se quiserem. Havendo sentimentos de escassez de Carícias entre as pessoas, haverá também uma falta de preparo para tomadas de decisão. 
Outro conceito fundamental para AT é a Síndrome da passividade (comportamentos passivos e Desqualificação apresentados por Schiff e Schiff (2010), que são adotados por pessoas que desqualificam, por exemplo, a possiblidade de resolução de um problema ou identificação de um estímulo. Os autores identificaram quatro tipos de Comportamentos passivos diante de um problema, que fazem parte do quadro clínico da Síndrome de passividade: não fazer nada, super adaptação, agitação, incapacitação e violência. A Desqualificação é uma manifestação observável que tem por definição "ações externas e internas que as pessoas empregam para evitar respostas autônomas aos estímulos, problemas ou opções, a fim de satisfazer suas necessidades ou atingir objetivos dentro da estrutura de relacionamentos simbióticos patológicos" (Schiff \& Schiff, 2010, p. 32). A Desqualificação é um dos mecanismos internos para a manutenção do quadro de referência, porém o ser humano possui uma força natural para se desenvolver e crescer (Mellor, 2017). Quanto à classificação das Desqualificações, Mellor e Schiff (2010) identificam-nas de acordo com a área, o tipo e o modo: desqualificação da existência de estímulos, problemas ou opções; desqualificação do significado; desqualificação das possibilidades de mudança; e desqualificação da própria habilidade ou da habilidade de outra pessoa em reagir de forma diversa aos estímulos, de resolver problemas ou de fazer algo diferente ou eficiente.

Essa capacidade de analisar ou não as diferentes possibilidades diante de um problema, estímulo ou opção depende de como nos sentimos e nos comportamos diante dos outros e do mundo.

O último conceito a ser tratado aqui é o de Script. Segundo Berne (1988, p. 36), Script é "Um plano de vida baseado numa decisão feita na infância, reforçada pelos pais, justificado por acontecimentos subsequentes e culminando com uma alternativa escolhida". O autor refere-se ao Script como um sistema formado por sete elementos que compõem o Aparelho de Script, que são: desfecho, injunção, provocação, liberação interna, prescrição, padrões parentais e demônio.

Através desses conceitos, podemos identificar e mensurar o nível de consciência emocional das pessoas, conforme proposto por Steiner e Perry (1997), especificamente por meio do Questionário de Consciência Emocional, cujos resultados podem ser diagramados numa escala denominada Escala de Consciência Emocional. Essa escala é composta por seis níveis (insensibilidade, sensações físicas, experiência primitiva, diferenciação/causalidade, empatia e interatividade), por meio dos quais podemos mensurar o nível de consciência no respectivo momento da vida em que o teste é feito. A seguir, vamos identificar do menor ao maior nível de consciência.

1- Insensibilidade: quando não temos a consciência dos sentimentos, "Traumas psicológicos podem nos atingir com tanta frequência que nossas mentes os repelem, congelando-nos Emocionalmente, entorpecendo-nos como uma forma de protegermo-nos destas dores" (Costa, Santos, \& Alves, 2012, p. 36).

2- Sensações físicas: as pessoas começam a perceber sintomas físicos (dores, aperto no peito, alteração respiratória), mas não percebem a que emoção estão relacionados. Por vezes, usam drogas para combater as sensações físicas cuja causa é emocional. Assim continuam com os mesmos problemas emocionais (Steiner, 2019).

3- Experiência primitiva: "Ao invés de tomarmos conta de nossa emoção, ela toma conta de nós" (Costa, Santos, \& Alves, 2012, p. 37). Neste estado, ficamos muito vulneráveis, sem entender o que sentimos, podendo haver explosões emocionais descontroladas. Podemos, ainda, ultrapassar a Barreira verbal quando despertamos para as nossas necessidades e nos apropriamos das sensações físicas e emoções para verbalizar sobre elas e como isso nos afeta (Steiner, 2000).

4- Diferenciação: o indivíduo identifica o que sente e o que se encontra por trás desse sentimento, exemplo: em uma crise de ciúme, é possível perceber que o sentimento principal é a raiva. Começamos a dar nomes aos nossos sentimentos de uma forma mais segura e genuína. Aqui, surge a causalidade, simultaneamente com a diferenciação, quando começamos a compreender o motivo de sentirmos o que sentimos. "Começamos a revelar a alquimia das 
emoções, de que forma nossas tendências emocionais combinam com as tendências emocionais do outro" (Steiner \& Perry, 1997, p. 49).

5- Empatia: à medida que nos conscientizamos de nossas emoções, começamos a perceber e intuir as emoções dos que nos cercam. Steiner e Perry asseguram que "A empatia é uma forma de intuição das emoções”. Há uma sinergia entre a intuição e a empatia. "O feedback sincero é a única forma de ampliar as próprias intuições empáticas" (Steiner \& Perry, 1997, p. 49-51).

6- Interatividade: não basta ser um bom empata, precisamos saber o que fazer com esta percepção. A interatividade emocional é o nível mais sofisticado de consciência, permitindo aos empatas trafegar em situações emocionais intensas (Steiner \& Perry, 2000).

\section{Metodologia}

Para a realização deste estudo, optou-se pela pesquisa avaliativa, apoiada pela abordagem quantitativa. Para Laville e Dionne (1999, p. 43) a abordagem quantitativa "pretende tomar a medida exata dos fenômenos humanos e do que os explica... Consequentemente, deve escolher com precisão o que será medido e apenas conservar o que é mensurável de modo preciso".

O projeto de pesquisa foi aprovado pelos Comitês de Ética da Plataforma Brasil, CAAE n. 32812720.3.0000.5336, e da Universidad Iberoamericana, ata n. CR-067. Para atender os preceitos éticos, cada docente que aceitou participar da pesquisa e assinou o Termo de Consentimento Livre e Esclarecido (TCLE) foi orientado a não incluir qualquer nome que o identificasse e a criar um nome fictício para o pré-teste, de preferência incomum, memorizando-o, pois precisaria usá-lo no pós-teste. O pré-teste foi aplicado antes do início do Curso 101 e o pós-teste no final do curso.

O Questionário de Consciência Emocional utilizado na pesquisa conta com seis perguntas, e cada questão apresenta seis afirmativas. Assim, as respostas são diagramadas junto à Escala de Consciência Emocional, que possui variação entre 0\% e 100\% no nível de consciência. Essas seis afirmativas (A, B, C, D, E, F), cujas respostas são "sim", "não" ou "não sei", projetam o nível de consciência emocional em que a pessoa se encontra naquele momento da vida. As questões A avaliam a sensibilidade emocional, as questões B verificam os sintomas físicos, as perguntas C referem-se à experiência primitiva, as questões D avaliam a diferenciação, as perguntas E encarregam-se da empatia, as questões F, da interatividade. Evidencia-se através da escala o que é necessário para sermos mais competentes ao lidar com nossas emoções (Steiner \& Perry, 1997, p. 3943).

O estudo contou com a participação de 20 docentes de uma instituição de cursos técnicos e superiores do sul do Brasil, na cidade de Porto Alegre, Rio Grande do Sul.

Os dados foram analisados no programa Statistical Package for Social Sciences versão 20.0 (SPSS Inc., Chicago, IL, USA, 2008) para Windows, sendo que, para critérios de decisão estatística, foi adotado o nível de significância de 5\%. Primeiramente, foi realizada a análise das variáveis, conforme a natureza das medidas. As variáveis quantitativas foram descritas por média e desvio padrão ou mediana e intervalo interquartílico, e as variáveis categóricas foram descritas por frequência absoluta e relativa.

A comparação das avaliações pré e pós-teste da aplicação do Curso 101 - Introdução à AT foi realizada pelo teste não paramétrico de Wilcoxon Signed Rank. Duas amostras de dados são combinadas se vierem de observações repetidas do mesmo sujeito. Usando o Wilcoxon Signed-Rank Test, podemos decidir se as distribuições da população de dados correspondentes são idênticas, sem presumir que seguem a distribuição normal. É um teste de hipóteses não paramétrico utilizado quando se deseja comparar duas amostras relacionadas, amostras emparelhadas ou medidas repetidas em uma única amostra. Ele é por vezes referido como o teste $\mathrm{T}$ de Wilcoxon e o teste estatístico é relatado como um valor de $\mathrm{T}$. 
Para a realização do Curso 101 e, portanto, da intervenção proposta na pesquisa, abriu-se uma disciplina, denominada Introdução à AT, Curso 101, na Plataforma Moodle da instituição do estudo. Foram postadas todas as informações referentes ao curso, como o programa, as datas e os horários, além de exercícios para que os participantes pudessem acompanhar os conteúdos semanais. O pré e o pós-teste e o TCLE foram disponibilizados em links.

Para que os docentes pudessem ter acesso à proposta, o curso foi divulgado por meio de fôlderes e cartazes em ambiente virtual, foram enviadas também mensagens de lembrança sobre o estudo. No desenvolvimento das atividades, as aulas foram gravadas e os exercícios postados, assim como as referências de acesso a publicações relacionadas ao conteúdo trabalhado.

\section{Resultados e Discussão}

Com a pandemia, o Curso 101 - Introdução à AT teve que sofrer alterações em relação ao formato pretendido inicialmente. Esse tipo de curso antes era realizado aos finais de semana (sexta e sábado) de forma presencial; nesta pesquisa, ocorreu remotamente

Para facilitar o acesso dos docentes ao curso, as direções da instituição definiram os melhores dias e horários para sua realização, ofertada em cinco módulos com duração média de $2 \mathrm{~h}$ a $2 \mathrm{~h} 30$, somando um total de $12 \mathrm{~h}$. Oferecido para duas turmas durante a semana, para melhor acomodar a escolha de cada professor, todas as aulas foram gravadas para aqueles que não pudessem comparecer nesses dias. Além disso, no início e ao final das aulas, havia o momento do brifing, quando as dúvidas eram dirimidas e algumas situações reais (conflitos de sala de aula) debatidas.

O envolvimento da própria prática na formação de docentes é uma das condições defendidas por Zwierewicz et al. (2020). Para as autoras, os desafios discutidos localmente servem de referência para a construção de possibilidades, especialmente quando as alternativas se dinamizam no contexto dos docentes implicados nos processos formativos.

Para avaliar os impactos da formação, o instrumento da pesquisa, ou seja, a Escala de Consciência Emocional, foi disponibilizado via Google forms. Primeiro, solicitou-se a assinatura do TCLE, com 100\% de confirmação. Depois, um nome fictício,

Em relação ao perfil, dos 20 participantes, 18 eram mulheres (90\%) e 2 homens (10\%), as idades variaram entre 24 e 69 anos. Entre as profissões, encontraram-se enfermeiros, psicólogos, pedagogos, farmacêuticos e fisioterapeutas, com especialização, mestrado e doutorado.

Outra questão abordada relacionou-se a acompanhamento terapêutico ou psicológico. O resultado indicou que 16 pessoas (80\%) não fazem terapia e 4 o fazem (20\%).

\section{Sobre a consciência emocional}

Os resultados confirmam diferenças estatisticamente significativas no nível empatia (E) e interação (F), ampliando os níveis de consciência emocional, conforme pode ser observado na Tabela 1 e na Figura 1, onde são registrados os resultados tanto do pré-teste como do pós-teste. 
Tabela 1. Pré e Pós-Teste.

\begin{tabular}{cclc}
\hline \multicolumn{1}{c}{ Pré-Teste } & \multicolumn{1}{c}{ Pós-Teste } \\
\hline Nível A & 23 & Nível A & 24 \\
Nível B & 27 & Nível B & 21 \\
Nível C & 40 & Nível C & 40 \\
Nível D & 79 & Nível D & 81 \\
Nível E & 61 & Nível E & 80 \\
Nível F & 81 & Nível F & 94 \\
\hline
\end{tabular}

Nota: Da pesquisa. Fonte: Autores.

Figura 1. Comparação entre pré e pós-teste do conjunto dos participantes da pesquisa em relação a cada um dos seis níveis de consciência emocional.

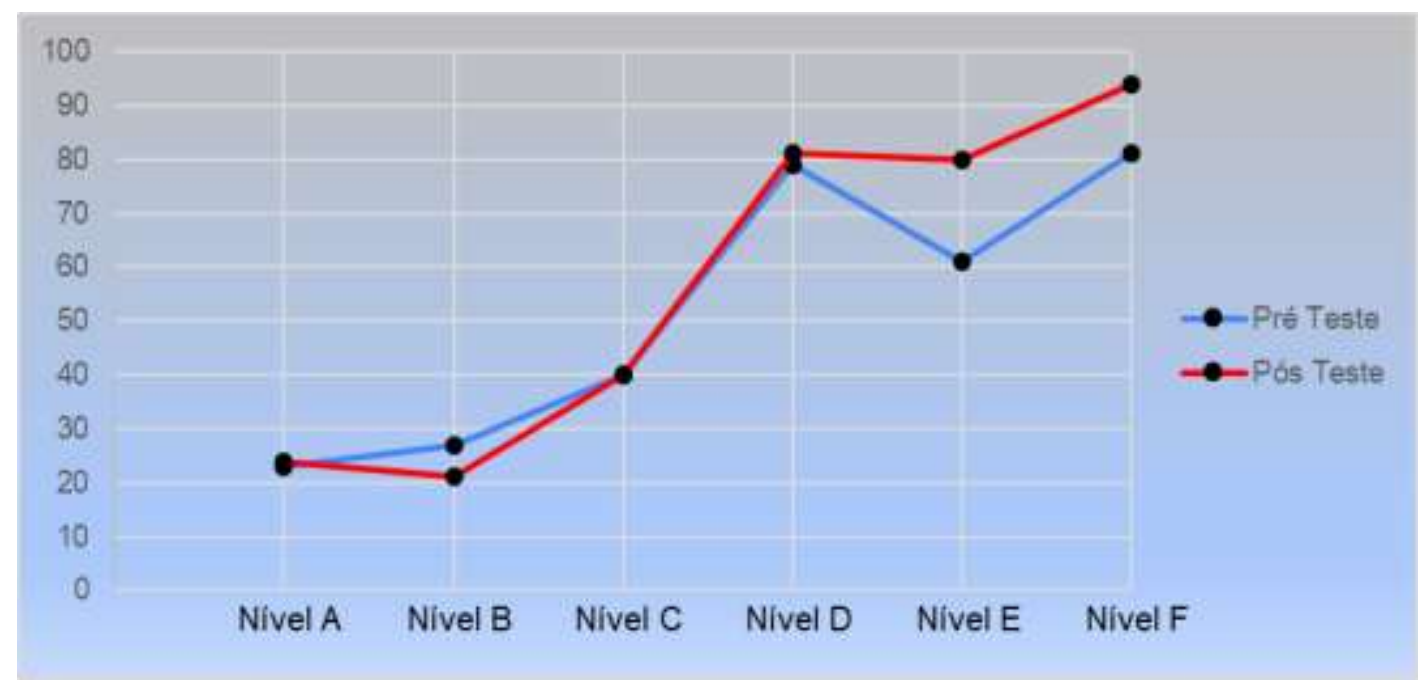

Nota: Da pesquisa. Fonte: Autores.

Dos seis níveis de consciência emocional, os dois últimos (empatia e interatividade) apresentaram diferença estatisticamente significativa. Com valor de $\mathrm{p}=0,005$, houve diferença estatisticamente significativa entre os valores observados para o quinto nível empatia (E) entre o pré e o pós- teste. Nossas percepções empáticas surgem quando nos tornamos mais conscientes dos nossos sentimentos e os sentimentos das outras pessoas. Nesse nível, percebemos e intuímos a complexidade e a sutileza das emoções. A empatia traz a possibilidade de ampliar as relações interpessoais e torná-las ainda mais significativas. Ela aumenta a capacidade de compreender emocionalmente o ponto de vista ou as ações do outro, expande a competência para a resolução de conflitos dentro de casa e nos ambientes corporativos, tornando o clima organizacional mais saudável. A escuta empática produz mais conexões entre as pessoas, consequentemente mais confiança entre elas. Dessa forma, tende a ajudar na redução do estresse (Erskine, 2016).

Com valor de $\mathrm{p}=0,027$, houve diferença estatisticamente significativa entre os valores observados para o sexto e último nível interatividade (F) entre o pré e o pós-teste. Ou seja, aumentou significativamente no pós-teste. Em ambientes coletivos, como as escolas, os profissionais se relacionam e interagem a todo momento, trocando experiências e percepções cada um com seu modo de agir e em alinhamento com as estratégias da empresa e com a operacionalização da engrenagem organizacional. A interatividade é importante pois influencia os processos organizacionais, o que torna a educação emocional ainda mais valiosa. A expansão da consciência emocional no nível da interatividade qualifica muito essas trocas. Neste nível, a pessoa sabe o que fazer diante das situações emocionais. "A Interatividade é o elo entre na relação entre a Consciência Emocional e a Educação Emocional” (Steiner \& Perry, 1997, p. 54). 
Nos três últimos níveis, diferenciação/causalidade (D), empatia (E) e interatividade (F), a pessoa sabe a causa do que sente e porque sente, reconhece os sentimentos em si e nas outras pessoas empaticamente. A pessoa entende as emoções e começa a fazer escolhas de como e quando expressá-las. Com seu EDE adulto, tem maior capacidade de desenvolver seu nível de consciência para avaliar a realidade e produzir as mudanças desejadas em sua vida pessoal e profissional.

Em relação ao primeiro nível, insensibilidade (A), quando a pessoa é incapaz de sentir, mesmo diante de fortes emoções, o valor foi de $\mathrm{p}=0,805$, não havendo, portanto, diferença estatisticamente significativa entre os valores observados entre o pré e o pós-teste. Nesse nível, a pessoa não é capaz de perceber suas emoções, não consegue discernir seus sentimentos e flutua entre a explosão de raiva e a culpa, sugerindo o aparecimento dos comportamentos passivos, como agitação, incapacidade ou violência (Schiff \& Schiff, 2010, p. 32). Esse é o nível de maior alienação emocional. Assim como não sente dor, a pessoa dissocia-se de alegrias, podendo apresentar sinais como rubor facial ou tom de voz alterado evidentes para os outros, porém ela se mantém "congelada". Logo, conclui-se que, estruturalmente, o EDE da pessoa, neste estágio, encontra-se em Pai ou Criança. Assim, a comunicação é pautada na Transação cruzada ou ulterior, com propensão à produção de Jogos Psicológicos e Desqualificações (Berne, 1988).

Com relação ao segundo nível, sensações físicas (B), as sensações da emoção aparecem desprovidas da consciência da emoção. $\mathrm{O}$ valor $\mathrm{p}=0,334$ demonstra que não houve diferença estatisticamente significativa entre os valores observados neste segundo nível entre o pré e o pós-teste. Neste nível, as pessoas podem sentir sinais e sintomas como palpitação, sudorese, calafrios, boca seca, entre outros, mas é comum que não saibam a que emoção eles estão ligados. Entre as opções, tem se tornado comum utilizar medicações para suprimir efeitos produzidos por emoções desconhecidas, tamponando-as ainda mais. Assim, os problemas emocionais continuam sem solução, produzindo desequilíbrio no corpo e acarretando piores efeitos. Nestes casos, Erskine (2016) defende a Contaminação do EDE Adulto. Segundo Berne, a Contaminação é a invasão de uma parte de um EDE por outro EDE. Neste caso, o material do Pai ou da Criança "vazou" para o EDE Adulto (Berne, 1988).

Com valor de $\mathrm{p}=0,971$, observa-se que também não houve diferença estatisticamente significativa entre os valores observados para o terceiro nível experiência primitiva (C) entre o pré e o pós-teste. Neste nível, a pessoa possui a percepção do que está sentindo, mas não compreende nem comanda a emoção. Quando as emoções se intensificam, há o temor da perda de controle. Isso pode acarretar em alienação emocional como modo de se proteger, o que nos induz a pensar que nesta fase a energia flutua junto entre EDE P e C. Também pode estar havendo escassez de carícias, manifestada em atitudes como "Não dê Carícias (a si ou aos outros); Não peça Carícias; Não aceite Carícias...” (Steiner, 1976 e 1980).

Entre a experiência primitiva (C) e a diferenciação (D) existe uma "travessia", um rompimento da Barreira verbal em que há o espaço da comunicação, a possibilidade de falar e ser compreendido sem julgamentos, o que amplia as possibilidades da conectividade. Assim, a pessoa começa a compreender melhor as emoções e a se comunicar empaticamente, interagindo de modo mais qualificado. As transações complementares se tornam mais nítidas, com menor risco de contaminação de EDE (Berne, 1988).

Com valor $\mathrm{p}=0,589$, observou-se também que não houve diferença estatisticamente significativa entre os valores observados para o quarto nível diferenciação (D) entre o pré e o pós-teste. Neste estágio, a pessoa toma consciência das emoções mais básicas, reage emocionalmente compreendendo o que sente e porque sente.

Com os resultados dos três primeiros níveis (insensibilidade, sensações físicas e experiência primitiva), infere-se que um grupo fechado de profissionais, como este grupo de professores participantes da pesquisa, pode ter temido julgamentos e não desejado se expor, protegendo-se ou até mesmo ocultando determinadas sensações

Deduz-se que as maiores mudanças nesses três níveis de ampliação de consciência poderiam ser diferentes em ambientes onde as pessoas pouco se conhecem ou, ao contrário, quando possuem maior intimidade. Elas normalmente precisam se sentir à vontade para falar de si, seus dramas, tristezas e alegrias, sem medo ou preocupação relacionados ao que 
os outros vão pensar ou a como vão reagir. Ao se apropriar das emoções e dos sentimentos, o rompimento de Barreira Verbal transpõe a pessoa a outros níveis de conexão e autonomia.

\section{Conclusão}

Considerando que o objetivo da pesquisa foi saber da influência do Curso 101 - Introdução à AT na compreensão, escuta e expressão das emoções de docentes de uma instituição de cursos técnicos e superiores do sul do Brasil, para a ampliação do nível de consciência emocional, o estudo comprovou uma resposta positiva.

$\mathrm{O}$ resultado do teste $\mathrm{T}$ de Wilcoxon demonstra que a diferença entre os pré-testes e os pós-testes foi estatisticamente significativa, especificamente em dois níveis: empatia e interatividade. Esses níveis implicam na ampliação da capacidade de se posicionar no lugar do outro, melhorando também a forma de interagir, o que demonstra a expansão dos níveis de consciência emocional.

Com a empatia, nos conscientizamos de nossas emoções e percebemos as emoções dos outros. A escuta empática representa a boa relação empática, pois transmite o interesse em incluir o outro e acolhê-lo com compreensão.

Quanto à interatividade, ela se relaciona ao saber o que fazer com a empatia. Evidencia, portanto, uma capacidade mais qualificada de interagir adequadamente com a situação e com o ambiente.

Além disso, a constatação de que a curva do pré-teste em relação ao pós-teste foi muito parecida, desde o primeiro até o sexto nível, nos possibilita dizer que o grupo possui em ambas as curvas um comportamento grupal uniforme, tanto no pré como nos pós-teste. Nesse sentido, destaca-se que, na coleta de dados, os participantes se identificaram como "nós", o grupo de professores.

Em relação às dificuldades da pesquisa, ao longo do estudo houve complicações e limitações atreladas à pandemia como um fator dificultador. A sensibilização para a participação na pesquisa, as aulas, os exercícios e as vivências em grupo foram feitas virtualmente, quando o normal nos Cursos 101 de AT seria a realização presencial.

Outra situação causada pela pandemia foi a sobrecarga dos professores, com aulas em quase todos os turnos, o que dificultou sua presença nos horários da disciplina, embora todas as aulas tenham sido gravadas na Plataforma Moodle. Por isso, alguns fizeram o pré-teste, mas não realizaram parte do curso e, consequentemente, o pós-teste ou vice-versa. Estes que não puderam participar integralmente da proposta não foram incluídos na amostra, que contou com um total de 20 professores participantes.

Destaca-se, ainda, a relevância de não restringir qualquer forma de apoio emocional dentro dos ambientes de ensino aprendizagem. É necessário apoiar novos modelos de interação para que o trabalho em sala de aula seja mais leve e tranquilo, minimizando-se as dificuldades vivenciadas num trabalho precário pela sobrecarga e desvalorização.

Como possibilidades para novas pesquisas, sugere-se uma revisão ampla de estudos correlatos sobre AT, publicados no Catálogo de Teses e Dissertações da Coordenação de Aperfeiçoamento de Pessoal de Nível Superior (CAPES), especialmente os realizados nos últimos cinco anos. A análise poderá fornecer um panorama dos avanços das pesquisas de pósgraduação sobre a temática no contexto nacional.

Da mesma forma, sugere-se a aplicação do Curso 101 - Introdução à Análise Transacional (AT) em outras instituições de ensino, sendo a coleta de dados realizada com apoio de entrevista. Dessa forma, poderão ser coletados dados que aprofundam condições subjetivas relacionadas à compreensão, escuta e expressão das emoções. 


\section{Referências}

Ammar, A. et al., (2020). Effects of COVID-19 home confinement on physical activity and eating behavior. Preliminary results of the ECLB-COVID19 international online-survey. Medrxiv, [s. 1.], 12(6), 1-23. https://www.medrxiv.org/content/10.1101/2020.05.04.20072447v1.full.

Atkinson, A. P.; Adolphs, R. (2005). Visual emotion perception: Mechanisms and processes. Em L. F. Barrett, P. M. Niedenthal, \& P. Winkielman (Eds.). Emotion and consciousness (150-182). Guilford. Barcelona: (MIDE).

Ávila, I. C. G., Souza, A. C. M. (2020). Desafios da docência: enfrentamentos do fazer pedagógico na formação dos professores na contemporaneidade. Educação Pública, 20(16).

Berne, E. (1977). Os Jogos da vida: a psicologia transacional e o relacionamento entre as pessoas. Artenova.

Berne, E. (1988). O que você diz depois de dizer olá? A psicologia do destino. Nobel.

Camargo, C. A. C. M.; Camargo, M. A. F.; Souza, V. O. (2019). A importância da motivação no processo ensino aprendizagem. Ciências Humanas. Revista Thema, 16(3), 598-606. http://periodicosnovo.ifsul.edu.br/index.php/thema/article/view/1284.

Costa, J. M. P.; Santos, B. H.; \& Alves, T. C. (2012). Das emoções ao sentimento: construindo um caminho com coração. Cidade.

Erskine, R. (2016). Transactional Analysis in Contemporary Psychotherapy. Karnac. Books Ltd. Londres NW3 5HT.ITAA, Journal. (2021). Itaaworld.org. https://itaaworld.org/transactional-analysis-journal.

Karpmn, S. (1968). Fairy Tales And Script Drama Analysis. https://karpmandramatriangle.com/pdf/DramaTriangle.pdf.

Laville, C. \& Dionne, J. (1999). A construção do saber: manual de metodologia da pesquisa em ciências humanas. https://edisciplinas.usp.br/pluginfile.ph p/287028/mod_resource/content/1/Laville\%2C\%20Christian\%20\%20Dionne\%2C\%20Jean_A\%20Construcao\%20do\%20Saber\%20\%28completo\%29.pdf

Libâneo, J. C., Oliveira, J. F. e Toschi, M. S. (2017). Educação escolar: políticas, estrutura e organização. Cortez.

Marques, R. \& Fraguas, T (2021). A formação do senso crítico no processo de ensino e aprendizagem como forma de superação do senso comum. Research, Society and Development, 10(7), 1-14. http://dx.doi.org/10.33448/rsd-v10i7.1665.

Mellor, K. \& Schiff, E. (2010). Premios Eric Berne. (1971-1997). UNAT-Brasil. (4a ed.).

Mellor, K. (2017). Life the hidden template, life energy the driving force, grounding the action. Transactional Analysis Journal, 47, 54-67. https://doi.org/10.1177/0362153716680377.

Nóvoa, A. (2017). Firmar a posição como professor, afirmar a profissão docente. Cadernos de Pesquisa, 47(166), 1106-1133 out/dez. https://www.scielo.br/pdf/cp/v47n166/1980-5314-cp-47-166-1106.pdf

Piccinino, G. (2018). Reflexões sobre Physis, Felicidade e Motivação Humana. Transactional Analysis Journal (TAJ), 48(3).

Rebolo, F. e Bueno, B. O. (2014). O bem-estar docente: limites e possibilidades para a felicidade do professor no trabalho. Acta Scientiarum. Education Maringá, 36(2), 323-331. https://periodicos.uem.br/ojs/index.php/ActaSciEduc/article/view/21222.

Reis, A. T. (2018). Análise crítica dos contextos de uma política de iniciação à docência: Projeto Bolsa Alfabetização da Secretaria de Educação do Estado de São Paulo. Tese doutorado em educação. PUC-SP, São Paulo.

Sales, Y. (Ed). (2020). Estudante mata dois colegas a tiros e fere quatro em escola de Goiânia. Journal El Pais. Recuperado de https://brasil.elpais.com/brasil/2017/10/20/politica/1508514051_919340.html.

Schiff, A. W. \& Schiff, J. L. (2010). Passividade. Prêmios Eric Berne. (4a ed). UNAT-BRASIL Analysis Treatment of Psychosis. New York: Harper \& Row. $\mathrm{TAJ}-\mathrm{v}$.

Silva, M. M. (2018). Inteligência emocional e sua aplicação no contexto educacional. Revista de Ciências e Humanidades Universidade Regional do Cariri.

Steiner, C. (1976). Os papéis que vivemos na vida: A Análise Transacional de nossas interpretações cotidianas [tradução: George Schlessinger]. Artenova.

Steiner, C. M. (1980). A economia de Carícias: Prêmios Eric Berne (1971-1997). (4a ed.). UNAT-BRASIL: Suliani Editografia.

Steiner, C. \& Perry, P. (1997). Educação Emocional: um programa personalizado para desenvolver sua inteligência Emocional. Objetiva.

Steiner, C. \& Perry, P. (2000). Educação Emocional: literacia Emocional ou a arte de ler emoções. Cascais, Pergaminho.

Steiner, C. (2019). Educação Emocional: o que o amor tem a ver com isso? Revista Brasileira de Análise Transacional-REBAT. UNAT BRASIL. ISSN 15178668 .

UNAT - Brasil (2019). Manual da União dos Analistas Transacional. Impresso.

UNAT - Brasil (2020). Regulamentações. União dos analistas transacionais. https://unat.org.br/portal/regulamentacoes.php.

Zwierewicz, M. et al., (2020). Formação-Ação de Docentes em Escolas Criativas e seus reflexos em atividades de leitura, produção e interpretação textual. Research, Society and Development, 9(9), 1-16. http://dx.doi.org/10.33448/rsd-v9i9.7546 